\title{
Peptidomic Analysis of Cultured Cardiomyocytes Exposed to Acute Ischemic-Hypoxia
}

\author{
Lijie Wu ${ }^{a}$ Hua Lib Xing Li ${ }^{a}$ Yumei Chen ${ }^{a}$ Qijun Zhang ${ }^{c}$ Zijie Cheng ${ }^{\text {a }}$ Yi Fan $^{\mathrm{a}}$ \\ Guixian Song $^{d}$ Lingmei Qian ${ }^{a}$
}

aDepartment of Cardiology, ${ }^{b}$ Department of Emergency, The First Affiliated Hospital of Nanjing Medical University, Nanjing, Jiangsu Province, 'Department of Cardiology, Yinzhou No. 2 Hospital, Ningbo, Zhejiang Province, 'Department of Cardiology, Jiangsu Taizhou People's Hospital, Taizhou, Jiangsu Province, China

\section{Key Words}

Peptidomics • Acute myocardial infarction • Cardiomyocytes • Mass spectrometry • Hypoxia • Tandem mass tag

\begin{abstract}
Background: Acute Myocardial Infarction (AMI) is a life-threatening cardiovascular disease involving disruption of blood flow to the heart, consequent tissue damage, and sometimes death. Peptidomics, an emerging branch of proteomics, has attracted wide attention. Methods: A comparative peptidomic profiling was used to explore changes induced by acute ischemichypoxia in primary cultured neonatal rat myocardial cells. Analysis of six-plex tandem mass tag (TMT) labelled peptides was performed using nanoflow liquid chromatography coupled online with an LTQ-Orbitrap Velos mass spectrometer. Results: A total of 220 differentially expressed peptides originating from 119 proteins were identified, of which 37 were upregulated and 183 were downregulated in cardiomyocytes exposed to hypoxia/ischemia conditions. Many of the identified peptides were derived from functional domains of proteins closely associated with cardiomyocyte structure or AMI. Conclusion: Numerous peptides may be involved in process of AMI. These results pave the way for future functional studies of the identified peptides.
\end{abstract}

\section{Introduction}

Acute Myocardial Infarction (AMI) is a life-threatening condition associated with cardiovascular disease, and the rate of mortality within 30 days following a heart attack is high [1]. Incidence of myocardial infarction is around 208 cases per 100,000 personyears [2]. AMI has grown to become a major global health burden. Therefore, a deeper understanding of its molecular basis could facilitate the development of new diagnostic methods and therapeutic strategies.

L. Wu and H. Li contributed equally to this study. 
Peptidomics is an emerging branch of proteomics that has attracted wide attention in recent years [3]. Peptidomics attempts to perform a quantitative and qualitative analysis of peptides in a given cell type, tissue or disease state. Through this method, a large number of both intracellular and secreted mammalian peptides have been identified [4-9]. Peptides are important bioactive molecules in their own right. Many endogenous signalling molecules and hormones are sequence and structure-specific peptides. For example, neuropeptides are a large class of neuroactive messengers that are intimately involved in the regulation of many biological processes such as pain perception [10], energy metabolism [11] and brain cognitive state [12]. A lot of hormones are endogenous peptides (e.g., insulin, growth hormone, erythropoietin). These small endogenous peptides play important roles in many physiological processes. Peptidomics has been succeeding in identifying endogenous bioactive peptides [13-15]. The challenge is identifying which are endogenous bioactive peptides and which are degradation products with no functional role.

Currently, peptidomic studies of AMI are very few. In the present study, we use primary cultured neonatal rat myocardial cells to explore the peptidomic changes induced by acute ischemic-hypoxia. A total of 220 differentially expressed peptides were identified (absolute fold change $\geq 1.5$ ), of which 37 were upregulated and 183 were downregulated in cardiomyocytes following hypoxia/ischemia. Some of the identified peptides were derived from the domains of proteins associated with cardiomyocyte structure or AMI. We predict that these peptides are involved in AMI. Further, our results provide insight that will be useful for future functional studies of AMI-associated peptides and will give us deeper understanding about AMI at the cellular level.

\section{Material and Methods}

\section{Culturing neonatal rat cardiomyocytes}

1-3-day-old neonatal rats were purchased from the Animal Center in Nanjing Qing Long Shan, China. Rats were disinfected with $75 \%$ ethanol and hearts were removed and immediately placed in cold phosphate buffered saline (PBS, Wisent, CA). Hearts were then cut into pieces and digested using $0.4 \%$ Type 2 collagenase / $0.6 \%$ pancreatin (Sigma, USA). Digestion was terminated by house serum (HS, Sigma) and samples were centrifuged at $1000 \mathrm{rpm}$ for $5 \mathrm{~min}$. Cell pellets were resuspended in Dulbecco's modified Eagle's medium (DMEM, Gibco, USA) containing 5\% fetal bovine serum (FBS, Gibco), 10\% HS and $1.2 \%$ penicillin / streptomycin (Wisent). Cells were incubated at $37^{\circ} \mathrm{C}$ for $120 \mathrm{~min}$ to separate cardiomyocytes and cardiac fibroblasts (CFs). After $2 \mathrm{~h}$, cardiomyocytes in suspension were seeded onto cell gelatin coated culture plates (Sigma). To prevent the growth of CFs, media was supplemented with $30 \mu \mathrm{g} / \mathrm{ml}$ bromodeoxyuridine (BRDU, Sigma) [16]. Cell purity was evaluated by indirect immunofluorescence staining with a monoclonal anti-Troponin T antibody. Animal Care and Management Committee of Nanjing Medical University approved the whole study protocol.

\section{Hypoxic-ischemic exposure}

Cells were cultured for 4 days. CMs were randomly assigned to two groups. The growth media of the hypoxic ischemia group was replaced by serum-free DMEM. Hypoxia was achieved by using an AnaeroPack System anaerobic jar (Mitsubishi Gas Chemical, JPN) equipped with an AnaeroPack and a methylene blue indicator to monitor oxygen depletion. The AnaeroPack System can deplete the concentration of oxygen to $<1 \%$ within $30 \mathrm{~min}[17,18]$. CMs were incubated for a further $1 \mathrm{~h}$ after anoxic conditions were reached. Meanwhile, the growth media of control group cells was changed to fresh normal DMEM with serum and cells were placed in an incubator (Thermo Scientific, USA) under normoxic conditions for the same length of time. Three independent experiments were carried out in our research.

Flow cytometry

Cell survival was evaluated by flow cytometry (BD ACCURI C6, BD Biosciences, USA) with propidium iodide staining (BD Biosciences). At the end of the hypoxia period, cells were digested with $0.25 \%$ trypsin (Wisent) and centrifuged at $1000 \mathrm{rpm}$ for $5 \mathrm{~min}$. After removal of the supernatant, cells were washed twice 


\section{Cellular Physiology Cell Physiol Biochem 2017;41:358-368

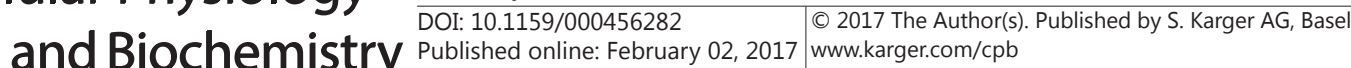

Wu et al.: Peptidomics Analysis of Cardiomyocytes

with PBS, then incubated with PI diluted in PBS for $10 \mathrm{~min}$ in the dark. Analysis was performed according to the relative fluorescence intensity of PI. Viable cells have a low fluorescence intensity and high forward scatter (FS).

\section{Peptide extraction}

Intracellular peptides were extracted as previously described [19]. To extract peptides, cardiomyocytes were seeded on $10-\mathrm{cm}^{2}$ plates and about 6 million cells were prepared for one sample. Media was aspirated completely and cells were added to $4 \mathrm{ml}$ of $80 \%$ methanol cooled to $-80^{\circ} \mathrm{C}$ in advance. After a $20 \mathrm{~min}$ incubation at $-80^{\circ} \mathrm{C}$, cells were agitated gently and centrifuged at $14000 \mathrm{~g}$ for $5 \mathrm{~min}$ at $4^{\circ} \mathrm{C}$. The supernatant containing peptides was transferred to a new eppendorf tube and the cell pellet was mixed with $500 \mu \mathrm{l}$ of $80 \%$ methanol and centrifuged again. The resulting supernatant was filtered through a 10,000 molecular weight cut-off (MWCO) Amicon Ultra-15 membrane (Millipore, USA). Extracts were lyophilized (FreeZone, Labconco, USA) and stored at $-80^{\circ} \mathrm{C}$. The concentration of total peptides/proteins was measured using the BCA protein assay (Pierce, USA).

\section{SDS-PAGE and Coomassie blue staining}

Peptides were separated by SDS-PAGE using a NuPAGE Bis-Tris Midi Gel (Life Technologies, USA) according to the manufacturer's instructions. Gels were stained for $15 \mathrm{~min}$ and destained overnight with $16.5 \%(\mathrm{v} / \mathrm{v})$ methanol / 5\% (v/v) glacial acetic acid.

\section{TMT labelling and mass spectrometry}

Before labelling, the quantity of peptides/proteins was normalized to $100 \mathrm{ug}$ in each sample. Six-plex TMT labelling (Thermo Scientific) was carried out according to the manufacturer's instructions. Briefly, 41 $\mu \mathrm{L}$ of anhydrous acetonitrile were added to each tube ( $0.8 \mathrm{mg}$ of TMT reagents) at room temperature and the reagents were dissolved by occasional vortexing for $5 \mathrm{~min} .41 \mu \mathrm{L}$ of the TMT Label Reagent were added to each $100 \mu \mathrm{g}$ sample carefully followed by incubation for $1 \mathrm{~h}$ at room time. The reaction was quenched with $8 \mu \mathrm{L}$ of $5 \%$ hydroxylamine for $15 \mathrm{~min}$ incubation. Samples were then stored at $-80^{\circ} \mathrm{C}$ until further analysis. Three normal control samples were labelled with reagents 126, 127 and 128, and three hypoxia/ischemia samples were labelled with reagents 129, 130 and 131. Analysis of labelled peptides was performed on a nanoflow LC (Easy-nLC, ThermoFisher Scientific) coupled online with an LTQ-Orbitrap Velos mass spectrometer (ThermoFisher Scientific). Reverse-phase separation of peptides was performed on each sample using two mobile phases consisting of buffer A ( $5 \%$ acetonitrile (ACN); $0.1 \%$ acid formic (FA), buffer B $(80 \%$ ACN, $0.1 \%$ FA). Reverse-phase separation of peptides was performed on each sample using two mobile phases consisting of buffer A ( $2 \%$ acetonitrile, $0.5 \%$ acid formic) and buffer B (98\% acetonitrile, 0.5\% acid formic). 96-91 \% A and 4-9\% B for $10 \mathrm{~min}, 91-67 \% \mathrm{~A}$ and 9-33\% B for $100 \mathrm{~min}, 67-50 \% \mathrm{~A}$ and $33-50 \%$ B for $30 \mathrm{~min}, 50-0 \% \mathrm{~A}$ and $50-100 \%$ B for $10 \mathrm{~min}, 100 \%$ B for $10 \mathrm{~min}, 95 \% \mathrm{~A}$ and $5 \% \mathrm{~B}$ for 10 $\mathrm{min}$. As peptides were eluted from the microcapillary column, they were electrosprayed directly into the mass spectrometer at a voltage of $1.9 \mathrm{kV}$. Peptide analysis was performed on a LTQ Orbitrap Velos in datadependent acquisition mode. For each cycle, survey full-scan MS spectra (m/z 400-1800) were acquired by the Orbitrap with a mass resolution of 60,000. Each full scan was followed by selecting the 10 most intense ions for collision-induced dissociation (CID) fragmentation (collision energy 35\%) and for higherenergy collisional dissociation (HCD) fragmentation (NCE 45\%). The HCD dissociation mode generates TMT reporter peptide ions. Singly charged or unassigned charge states were rejected. The $\mathrm{m} / \mathrm{z}$ isolation width of MS/MS fragmentation was set to 2 TH for ITMS and 1.2 TH for FTMS.

MS data analysis

Using in-house PEAKS software (version 7.0, Bioinformatics Solutions, Waterloo, Canada), MS/MS spectra were searched against a composite database containing rat protein sequences. A fusion targetdecoy approach was used for estimation of the false discovery rate (FDR) and was controlled at $\leq 1 \%(-10$ $\log P \geq 20.0$ ) at both protein and peptide levels. Peptides were only selected if identified in two or more separate spectra. Peptide relative quantification was performed using the TMT labelling approach in the PEAKS Q module. Feature detection was carried out separately on each sample using the expectationmaximization algorithm. Peptides from different samples with identical characteristics were aligned using a high-performance retention time alignment algorithm. The identification results were chosen to attach as the last step of the TMT labeling quantification.

\section{KARGER}




\section{Cellular Physiology \begin{tabular}{ll|l} 
and Biochemistry Published onlıne: February 02, 2017 & $\begin{array}{l}\text { (c) } 2017 \text { The Author(s). Published by S. Karger AG, Basel } \\
\text { www.karger.com/cpb }\end{array}$ \\
\hline
\end{tabular} \\ Wu et al.: Peptidomics Analysis of Cardiomyocytes}

\section{Bioinformatics analysis}

The isoelectric point (PI) and molecular weight (MW) of peptides were obtained using the online PI/MW tool (http://web.expasy.org/compute_pi/). Gene ontology (GO) and pathway analyses were used to investigate the potential functions of peptide precursors. In general, the threshold of significance was defined by the P-value and false discovery rate (FDR). In order to categorize isolated peptides and their precursor proteins, results were also subjected to Ingenuity Pathway Analysis (IPA, Ingenuity Systems, CA) which identifies canonical pathways.

\section{Statistical analysis}

Data are presented as means \pm SD. Student's $t$ test and one-way analysis of variance (ANOVA) with repeated measurements were applied, when appropriate, to determine the statistical significance of the differences. Data analysis was performed by SPSS software version 21 (SPSS, USA). A value of $\mathrm{P}<0.05$ was considered statistically significant.

\section{Results}

Identification of differentially expressed peptides

The purity of cardiomyocytes was identified by Immunofluorescence staining (Fig. $1)$. We selected $1 \mathrm{~h}$ as the ischemia exposure time point to avoid the release of cellular contents that would otherwise complicate the peptidomics analysis (Fig. 2). Then a $10 \mathrm{kDa}$ MWCO membrance was used to remove most of high molecular weight protein. Coomassie blue staining confirmed that most macromolecular proteins had been successfully removed (Fig. 3A). A statistical $p$ value $<0.05$ and a fold change of $\geq 1.5$ was applied, and a total of 4,506 peptide fragments ranging in size from 5 to 53 amino acid residues were identified in the six samples, with 220 differentially expressed peptides originating from 119 proteins. A total of 37 peptides were upregulated and 183 peptides were downregulated in the hypoxia group compared with the control group. Raw data have been uploaded to the public database: http://202.195.183.2/datacenter/. Differentially expressed peptides were visualized using a heatmap (Fig. 3B).

\section{Features of differentially expressed} peptides

We initially explored the MW, pI and the distribution of MW versus pI distribution of the differentially expressed peptides (Fig. 4A-F). The MW varied between 0.5-4 kDa and $\mathrm{pI}$ values also varied over a wide range. The MW of most upregulated peptides was between 0.5-1.4 and 2.0-2.9 $\mathrm{kDa}$, whereas most downregulated peptides fell into the

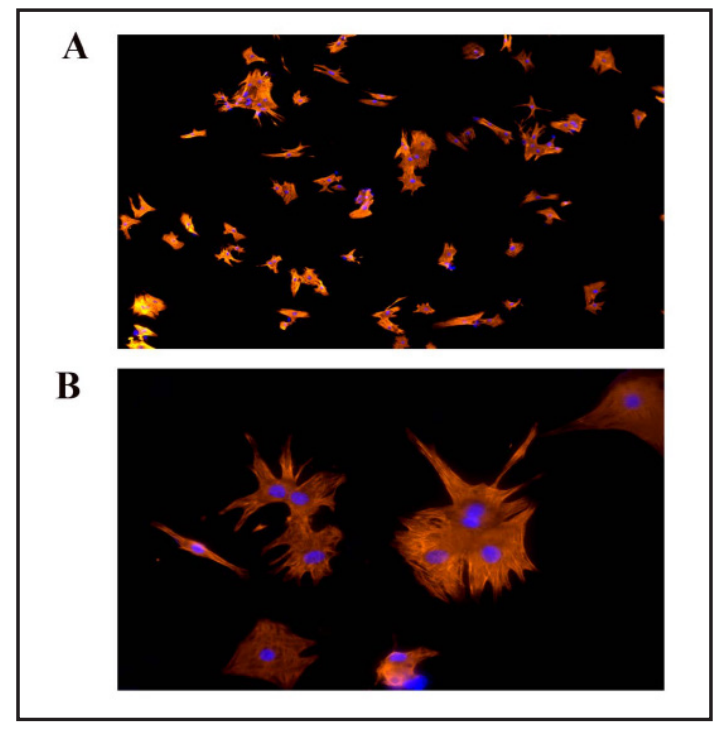

Fig. 1. Purification and identification of myocardial cells. Immunofluorescence staining using a monoclonal anti-Troponin $\mathrm{T}$ antibody (orange) to confirm cardiomyocyte purity. Nuclei are stained with DAPI (blue). (A) $\times 100$. (B) $\times 400$.

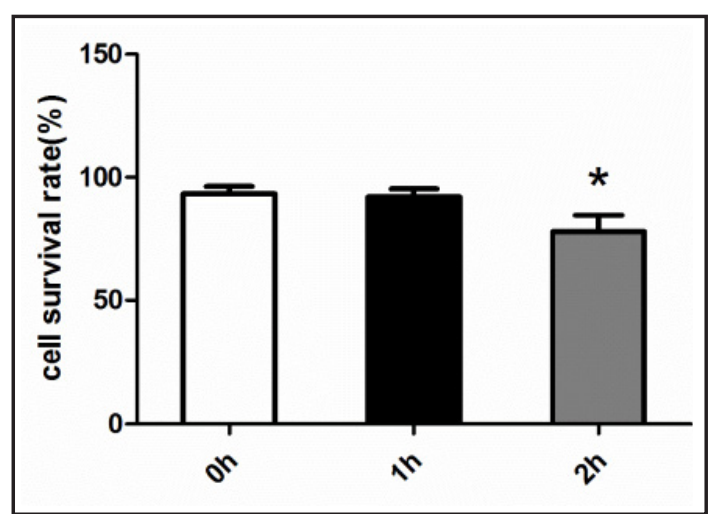

Fig. 2. The cell survival rate after hypoxic exposure. Flow cytometry using PI staining to assess cell survival rate at three time points $(0,1$ and $2 \mathrm{~h})$. There are no statistical differences at 0 and $1 \mathrm{~h}$, but the rate at $2 \mathrm{~h}$ is $\sim 15 \%$ lower than at $0 \mathrm{~h}\left(^{*} \mathrm{p}\right.$-value $<0.05 \mathrm{vs}$. the 0 h group). 


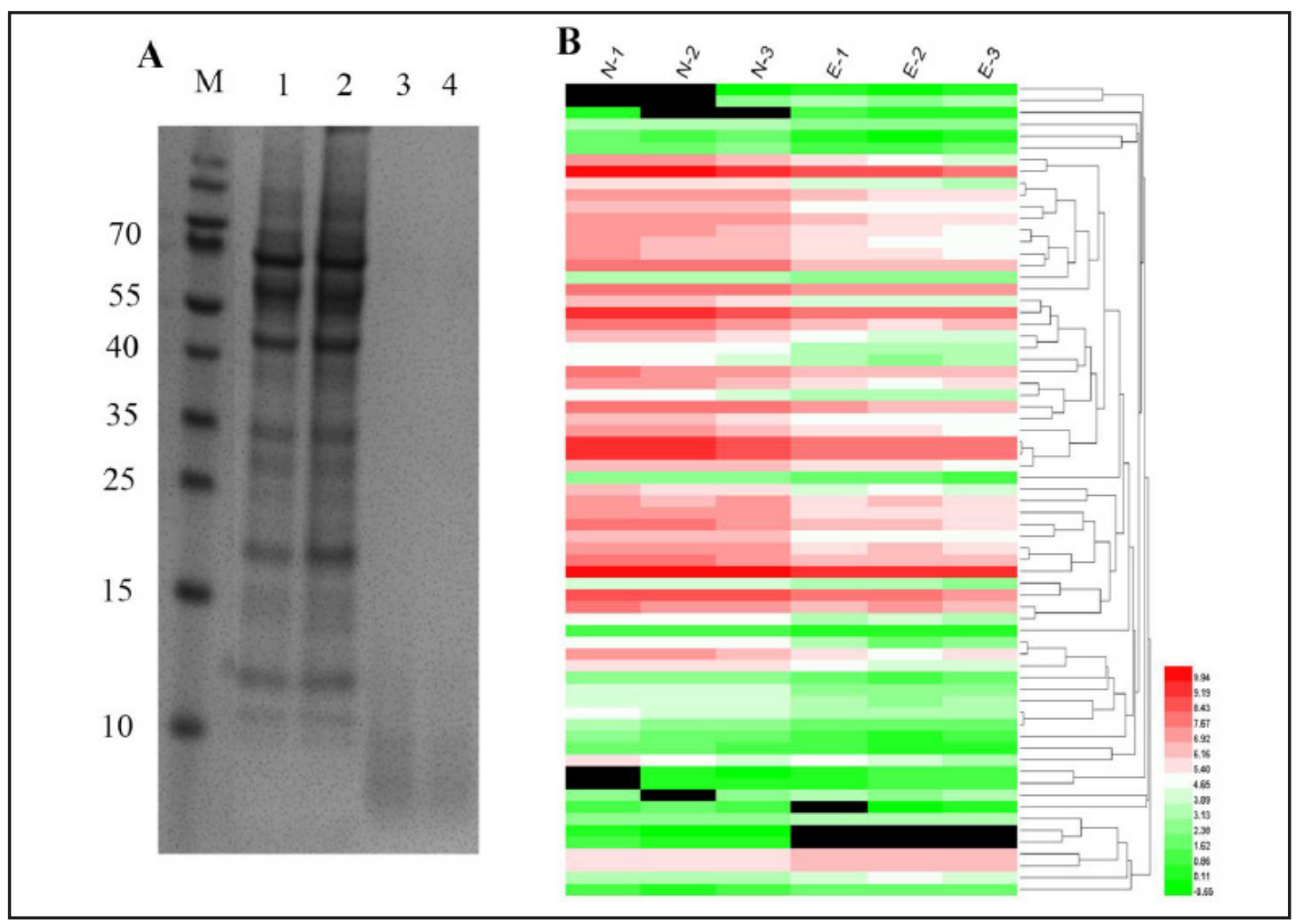

Fig. 3. Differently expression peptides profile in cardiomyocytes under normal and hypoxic condition. (A) SDS-PAGE and Coomassie blue staining of intracellular peptide samples before and after ultrafiltration. Most macromolecular proteins were removed successfully by ultrafiltration. $\mathrm{M}=$ marker. Units are $\mathrm{kDa}$. Lane 1, control group without filtration; lane 2, hypoxic/ischemic group without filtration; lane 3, purified peptides from the control group; lane 4, purified peptides from the hypoxic/ischemic group. (B) Heat map of peptides that are differentially expressed in normal and hypoxic ischemia-exposed cardiomyocytes. Red indicates high expression, green indicates low expression, and black indicates no expression. $\mathrm{N}=$ normal control group. $\mathrm{E}=$ hypoxic group.

0.7-1.3 kDa range. The pI values were similar, except a higher proportion of upregulated peptides fell into the $3-4$ range.

\section{Analysis of cleavage patterns}

We next searched for cleavage sites in all differentially expressed peptides to investigate possible functional changes in cardiomyocytes exposed to hypoxia/ischemia (Fig. 5A and 5B). According to the accepted nomenclature[20], the left side (i.e. C-term) and the right side (i.e. N-term) were named as P1 and P1', respectively. In upregulated peptides, the dominant amino acids of P1 and P1'were phenylalanine (F) and alanine (A), while in downregulated group they were asparagine $(\mathrm{N})$ and glycine $(\mathrm{G})$.

\section{GO and pathway analysis}

To preliminary explore the potential functions of those dys-regulated peptides in cardiomyocytes under hypoxic-ischemia condition, GO and pathway analysis were carried out base on of their protein precursors. In a search of the cellular component category, vesicle, ribosomal subunit, adherens junction, myofibril, mitochondrial respiratory chain, cytochrome complex, sarcomere, mitochondrial inner membrane, nucleus and cytoskeleton were the most populated sub-categories (Fig. 6A). For molecular function, protein binding, macromolecular complex binding, structural molecule activity, RNA binding, structural constituent of ribosome, nucleic acid binding, hydrogen ion transmembrane transporter 
A

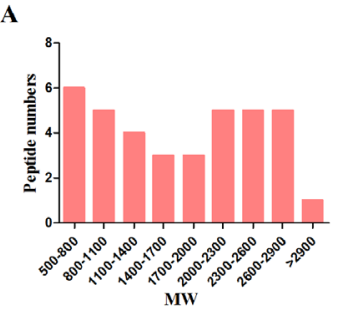

B

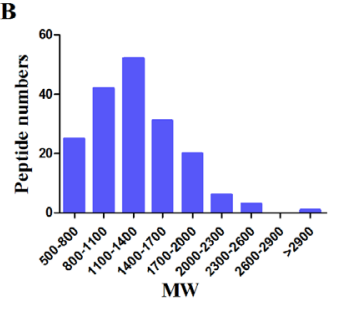

C

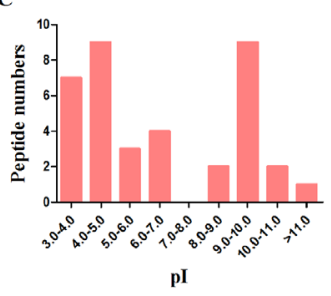

D

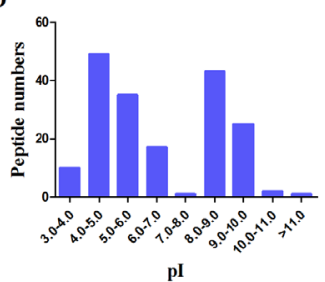

E

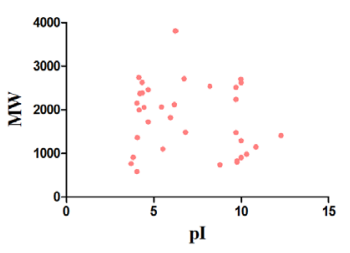

$\mathbf{F}$

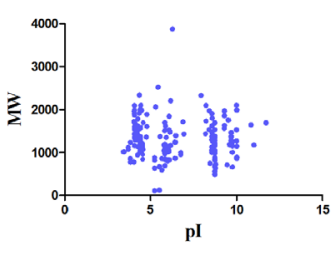

Fig. 4. Features of the differentially expressed peptides. (A) Molecular weight (MW) of upregulated peptides. (B) MW of downregulated peptides. (C) Isoelectric point (pI) of upregulated peptides. (D) pI of downregulated peptides. (E) Scatter plot of MW versus $\mathrm{pI}$ in upregulated and (F) downregulated peptides.
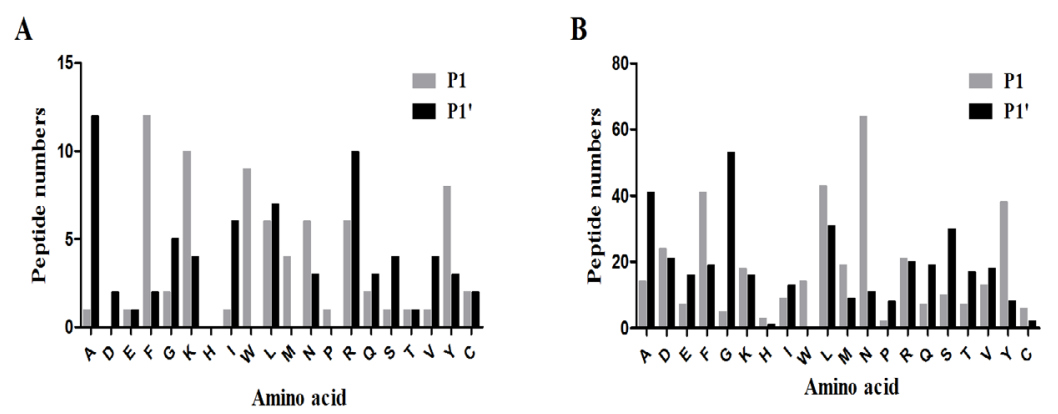

Fig. 5. Distribution of the cleavage sites in the identified peptides. (A) Distribution of the cleavage sites in the identified up-regulated peptides. (B) Distribution of the cleavage sites in the identified down-regulated peptides.

activity, cytoskeletal protein binding, oxidoreductase activity, and cytochrome-c oxidase activity were the dominantsub-categories (Fig. 6B). For biological process, nitrogen compound metabolic process, nitrogen compound biosynthetic process, nucleotide metabolic process, macromolecular complex subunit organization, translation, ATP metabolic process, peptide biosynthetic process, hydrogen ion transmembrane transport, amide biosynthetic process, and cytoskeleton organization were the most abundant sub-categories (Fig. 6C).

Ingenuity Pathway Analysis (IPA) was used to identify canonical pathways. In our survey of existing data, the protein precursors mainly involved the following pathways: EIF2 signalling, mitochondrial dysfunction, oxidative phosphorylation, actin cytoskeleton signalling, regulation of eIF4 and p70S6K signalling, mTOR signalling, calcium signalling, ILK signalling, phagosome maturation, RhoA signalling (Fig.6D).

\section{Cardiovascular system-associated peptides and precursor proteins}

In order to find the important peptides that play pivotal role in AMI, IPA and the UniProt database (http://www.uniprot.org/) were used to investigate the functions of differentially expressed peptides and their protein precursors. Finally, 9 precursors were found to be related to myocardium and hypoxia (Table 1). Many of the differentially expressed peptides were derived from functional domains of their corresponding precursor proteins (Table 1). 


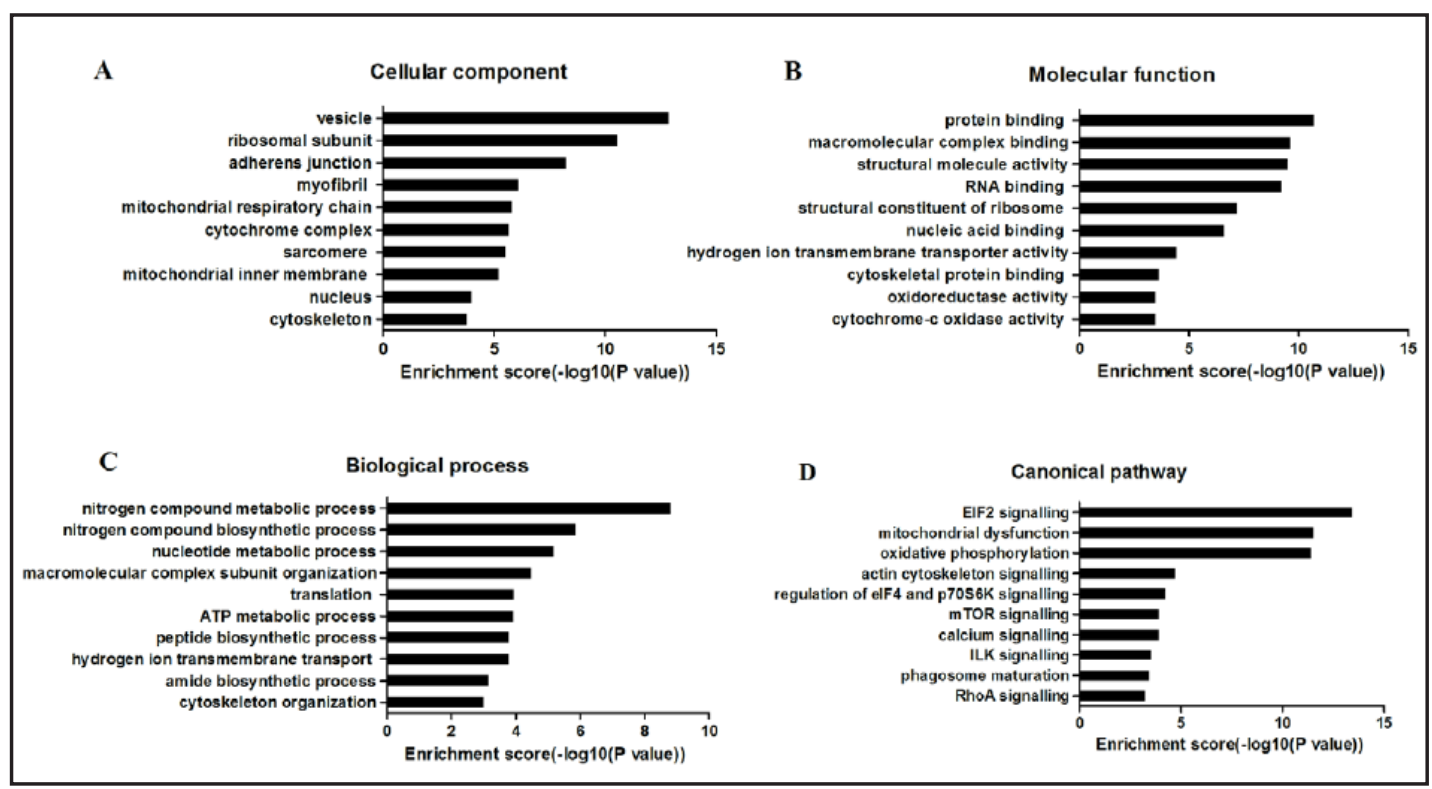

Fig. 6. Gene ontology (GO) and pathway analysis of precursor proteins from which differentially expressed peptides were derived. (A) The top ten cellular component categories. (B) The top ten molecular function categories. (C) The top ten biological process categories.(D) Mapping of precursor proteins of the differentially expressed proteins to canonical pathways.

Table 1. Protein precursors and identified peptides related to cardiovascular system

\begin{tabular}{|c|c|c|c|c|c|}
\hline Protein & Protein length & Fragment & Sequence & Location & Fold change \\
\hline \multirow[t]{2}{*}{ Alpha-crystallin B chain } & 175 & $\begin{array}{l}23-31 \\
27-31 \\
48-54\end{array}$ & $\begin{array}{l}\text { LFDQFFGEH } \\
\text { FFGEH } \\
\text { YLRPPSF }\end{array}$ & $\begin{array}{l}\text { HSP24-like chaperone } \\
\text { HSP20-like chaperone } \\
\text { HSP22-like chaperone }\end{array}$ & $\begin{array}{l}-1.57 \\
-1.61 \\
-1.67\end{array}$ \\
\hline & & $48-56$ & YLRPPSFLR & HSP23-like chaperone & 1.60 \\
\hline \multirow[t]{2}{*}{ Protein disulfide-isomerase } & 509 & $97-130$ & GVRGYPTIKFFKNGDTASPKEYTAGREADDIVNW & Thioredoxin & 2.90 \\
\hline & & $262-277$ & FLPKSVSDYDGKLSNF & Thioredoxin_6 & 1.88 \\
\hline \multirow[t]{10}{*}{ Myosin-7 } & 1935 & $55-65$ & EGGKVTAETEN & Myosin_N & -2.53 \\
\hline & & $87-95$ & IEDMAMLTF & Myosin_head & -2.00 \\
\hline & & $87-103$ & IEDMAMLTFLHEPAVLY & Myosin_head & 1.56 \\
\hline & & $267-277$ & LLEKSRVIFQL & Myosin_head & -1.51 \\
\hline & & $291-299$ & SNKKPELLD & Myosin_head & -1.85 \\
\hline & & $291-300$ & SNKKPELLDM & Myosin_head & -1.57 \\
\hline & & $368-386$ & QREEQAEPDGTEEADKSAY & Myosin_head & 1.54 \\
\hline & & $554-562$ & DNHLGKSNN & Myosin_head & -1.53 \\
\hline & & $571-582$ & GKQEAHFSLIHY & Myosin_head & -1.85 \\
\hline & & $686-693$ & NPLVMHQL & Myosin_head & -1.75 \\
\hline Myosin-6 & 1938 & $32-47$ & DIRTECFVPDDKEEYV & Myosin_N & -1.73 \\
\hline Unconventional myosin-IXb & 1980 & $154-158$ & LPELN & Myosin head & 1.71 \\
\hline Protein Txndc5 & 417 & $384-388$ & LLLFR & Thioredoxin & 1.82 \\
\hline Natriuretic peptides A & 152 & $131-142$ & GGRIDRIGAQSG & ANP & 1.55 \\
\hline \multirow[t]{2}{*}{ ADP/ATP translocase 1} & 298 & $62-71$ & PKEQGFLSFW & Mito_carr & 1.52 \\
\hline & & $81-89$ & YFPTQALNF & Mito_carr & 1.53 \\
\hline Prothymosin alpha & 112 & 002-018 & SDAAVDTSSEITTKDLK & Prothymosin & -1.61 \\
\hline
\end{tabular}

The protein with the most fragments was myosin-7, a member of the myosin superfamily, and peptides were derived from the myosin-head and myosin- $\mathrm{N}$ (myosin N-terminal SH3like) domains. In addition, 4 peptides were derived from the $\alpha$-crystallin B chain (CRYAB), a small heat-shock protein (sHSP), which has been shown to perform a protective function in cardiomyocytes [21, 22]. The protein disulfide-isomerase (PDI) which has been proved to be a survival factor in ischemia also has two fragments [23]. 


\section{Discussion}

Our study is the first report on qualitative and quantitative comparison of differently expressed peptides in normal and hypoxia-exposed cardiomyocytes using differential peptidomics.

Although there is no available technology that can measure all peptides at present, our study has been identified 4,506 peptide fragments, which is far more than other peptidomics studies $[6,24]$. To ensure the purity of extracted peptides, a $10 \mathrm{kDa}$ MWCO membrane which could be capable of removing most high molecular weight proteins without compromising peptide recovery was used during sample preparation.

Numerous studies have shown that proteases play a key role as regulators of disease development and progression in apoptosis [25], cancer [26, 27] and inflammatory disorders [28]. Proteases also play a key role in the development of heart diseases. For example, matrix metallo proteinases contribute to the progression of left ventricular dysfunction and remodeling associated with chronic heart failure [29]. Cathepsins L may participate in the atherosclerotic process [30]. Prolyl-4-hydroxylase domain 3 impairs the myocardial response to ischemia [31]. In our database, some peptides with different abundances were derived from the same precursor protein. We think the phenomenon is mainly related to proteolytic processing. The proteases are important factors which regulate the levels of proteins or peptides. In many cases, the protease specificity is reflected by the cleavage events catalysed by the enzyme. Moreover, the biological function of cleavage products such as the peptides identified in this study can be greatly influenced by the precise position of the protease cleavage site $[32,33]$. Hence, we analysed the cleavage sites in all differentially expressed peptides (Fig. 4). In total, 20 amino acids differed in the identified cleavage sites, indicating that proteases cleave proteins according to specific rules.

Gene Ontology generates dynamic results for many eukaryotes that are useful despite the fact that our knowledge is accumulating and changing rapidly [34]. GO analysis of our results revealed that the main cellular component of many of the identified peptides was associated with hypoxic ischemia. For example, mitochondrial respiratory chain, mitochondrial inner membrane, cytochrome complex were highly abundant. This is understandable because under hypoxic conditions, mitochondria represent a threat to the cell due to their capacity to generate toxic reactive oxygen species (ROS) at complexes I and III of the electron transfer chain (ETC), and which are a known feature of ischemia [35-38].

Canonical pathways were generated using IPA software (Fig. 6), and "mitochondrial dysfunction" was identified as a highly prevalent term. EIF2 signalling had the highest -log(pvalue), and was clearly affected by hypoxia/ischemia in CMs. EIF2 signalling is involved in endoplasmic reticulum (ER) stress, and the ER-dependent apoptotic pathway is one of the mechanisms by which hypoxic injury is induced in cardiomyocytes [17, 39, 40].

In many cases, segmental functional peptides play part of the biological function similar to their precursor proteins [41-43]. We selected 9 protein precursors closely related to cardiomyocyte structure or AMI from the 119 precursor proteins identified, and listed the differentially expressed peptides that were derived from functional domains in these proteins. Many of the precursor proteins are known to be important in cardiomyocytes, including Myosin-7, Myosin- 6 and the unconventional myosin-IXb, which accounted for 12 of the identified peptides $[44,45]$. A further 4 peptides were derived from $\alpha$-crystallin B chain $(\alpha \mathrm{B}$-crystallin, $\mathrm{CRYAB})$, which is abundant in cardiac tissue. These peptides were from the HSP24-like, HSP20-like, HSP22-like and HSP23-like chaperones, respectively. In a previous study, overexpression of $\alpha \mathrm{B}$-crystallin using an adenovirus vector system protected adult cardiomyocytes and neonatal cardiomyocytes against ischemic injury [46]. Furthermore, $\alpha \mathrm{B}$-crystallin functions as a regulatory switch to modulate apoptosis in CMs by influencing mitochondria and the ER during cardiac hypertrophy and myocardial infarction [47].

The peptides 97-130 (GVRGYPTIKFFKNGDTASPKEYTAGREADDIVNW) and 262277 (FLPKSVSDYDGKLSNF) also caught our attention, since they are both derived from protein disulfide-isomerase (PDI), from the thioredoxin_1 and thioredoxin_6 domains, 


\section{Cellular Physiology Cell Physiol Biochem 2017;41:358-368

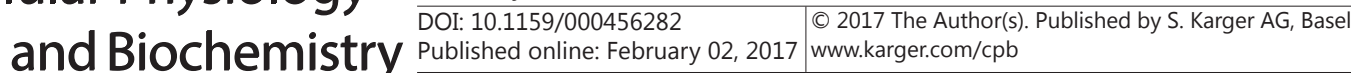 \\ Wu et al.: Peptidomics Analysis of Cardiomyocytes}

respectively. AMI can alter the workload of the ER, and ER stress can stimulate the unfolded protein response (UPR) in an attempt to balance the protein folding capacity, while destructive pathways can be activated to maintain ER homeostasis. Failure to rebalance protein folding activity in the ER can lead to apoptosis and cell death $[23,48$, 49]. PDI is a member of the thioredoxin superfamily and is mainly located in the ER where it exhibits linked but independent oxidoreductase and chaperone activities. PDI is critical for the UPR and the prevention of misfolding during myocardial ischemic injury. PDI is upregulated following hypoxia as part of the survival response to oxygen deprivation, and overexpression of PDI correlates with a decrease in cell death following AMI [23, 50-52]. PDI is therefore a survival factor in cardiomyocyte ischemia. We therefore predict that 97-130 (GVRGYPTIKFFKNGDTASPKEYTAGREADDIVNW) and 262-277 (FLPKSVSDYDGKLSNF) may be protective factors against hypoxia.

In summary, our differential peptidomics study is the first to qualitatively or quantitatively compare peptides in normal and hypoxic ischemia-exposed cardiomyocytes. The results suggest that numerous peptides may be involved in AMI, and provides insight for future functional analysis. Further investigations are needed to uncover the molecular mechanisms and biological functions of these peptides and their relevance to AMI.

\section{Acknowledgements}

This work was funded by a grant from the National Natural Science Foundation of China (Grant Nos. 81370278 and 81570209).

\section{Disclosure Statement}

The authors have declared that no conflict of interest exists.

\section{References}

1 Chung SC, Gedeborg R, Nicholas O, James S, Jeppsson A, Wolfe C, Heuschmann P, Wallentin L, Deanfield J, Timmis A, Jernberg T, Hemingway H: Acute myocardial infarction: a comparison of short-term survival in national outcome registries in Sweden and the UK. Lancet 2014;383:1305-1312.

2 Yeh RW, Sidney S, Chandra M, Sorel M, Selby JV, Go AS: Population trends in the incidence and outcomes of acute myocardial infarction. N Engl J Med 2010;362:2155-2165.

-3 Dallas DC, Guerrero A, Parker EA, Robinson RC, Gan J, German JB, Barile D, Lebrilla CB: Current peptidomics: applications, purification, identification, quantification, and functional analysis. Proteomics 2015;15:1026-1038.

4 Gelman JS, Sironi J, Berezniuk I, Dasgupta S, Castro LM, Gozzo FC, Ferro ES, Fricker LD: Alterations of the intracellular peptidome in response to the proteasome inhibitor bortezomib. PLoS One 2013;8:e53263.

-5 Rubakhin SS, Churchill JD, Greenough WT, Sweedler JV: Profiling signaling peptides in single mammalian cells using mass spectrometry. Anal Chem 2006;78:7267-7272.

6 Yin P, Knolhoff AM, Rosenberg HJ, Millet LJ, Gillette MU, Sweedler JV: Peptidomic analyses of mouse astrocytic cell lines and rat primary cultured astrocytes. J Proteome Res 2012;11:3965-3973.

7 Slavoff SA, Mitchell AJ, Schwaid AG, Cabili MN, Ma J, Levin JZ, Karger AD, Budnik BA, Rinn JL, Saghatelian A: Peptidomic discovery of short open reading frame-encoded peptides in human cells. Nat Chem Biol 2013;9:59-64.

8 Gelman JS, Sironi J, Castro LM, Ferro ES, Fricker LD: Peptidomic analysis of human cell lines. J Proteome Res 2011;10:1583-1592.

-9 Taylor SW, Nikoulina SE, Andon NL, Lowe C: Peptidomic profiling of secreted products from pancreatic islet culture results in a higher yield of full-length peptide hormones than found using cell lysis procedures. J Proteome Res 2013;12:3610-3619. 


\section{Cellular Physiology Cell Physiol Biochem 2017;41:358-368 and Biochemistry DOI: 10.1159/000456282 2010 (0) 2017 The Author(s). Published by S. Karger AG, Basel

Wu et al.: Peptidomics Analysis of Cardiomyocytes

10 Strand FL, Rose KJ, Zuccarelli LA, Kume J, Alves SE, Antonawich FJ, Garrett LY: Neuropeptide hormones as neurotrophic factors. Physiol Rev 1991;71:1017-1046.

11 Fouillen L, Petruzziello F, Veit J, Bhattacharyya A, Kretz R, Rainer G, Zhang X: Neuropeptide alterations in the tree shrew hypothalamus during volatile anesthesia. J Proteomics 2013;80:311-319.

-12 Rahman MM, Neupert S, Predel R: Neuropeptidomics of the Australian sheep blowfly Lucilia cuprina (Wiedemann) and related Diptera. Peptides 2013;41:31-37.

13 Baggerman G, Boonen K, Verleyen P, De Loof A, Schoofs L: Peptidomic analysis of the larval Drosophila melanogaster central nervous system by two-dimensional capillary liquid chromatography quadrupole time-of-flight mass spectrometry. J Mass Spectrom 2005;40:250-260.

14 Clynen E, De Loof A, Schoofs L: The use of peptidomics in endocrine research. Gen Comp Endocrinol 2003;132:1-9.

$\checkmark 15$ Hummon AB, Amare A, Sweedler JV: Discovering new invertebrate neuropeptides using mass spectrometry. Mass Spectrom Rev 2006;25:77-98.

16 Simpson P, Savion S: Differentiation of rat myocytes in single cell cultures with and without proliferating nonmyocardial cells. Cross-striations, ultrastructure, and chronotropic response to isoproterenol. Circ Res 1982;50:101-116.

17 Terai K, Hiramoto Y, Masaki M, Sugiyama S, Kuroda T, Hori M, Kawase I, Hirota H: AMP-activated protein kinase protects cardiomyocytes against hypoxic injury through attenuation of endoplasmic reticulum stress. Mol Cell Biol 2005;25:9554-9575.

-18 Tokudome S, Sano M, Shinmura K, Matsuhashi T, Morizane S, Moriyama H, Tamaki K, Hayashida K, Nakanishi H, Yoshikawa N, Shimizu N, Endo J, Katayama T, Murata M, Yuasa S, Kaneda R, Tomita K, Eguchi N, Urade Y, Asano K, Utsunomiya Y, Suzuki T, Taguchi R, Tanaka H, Fukuda K: Glucocorticoid protects rodent hearts from ischemia/reperfusion injury by activating lipocalin-type prostaglandin D synthase-derived PGD2 biosynthesis. J Clin Invest 2009;119:1477-1488.

19 Yuan M, Breitkopf SB, Yang X, Asara JM: A positive/negative ion-switching, targeted mass spectrometrybased metabolomics platform for bodily fluids, cells, and fresh and fixed tissue. Nat Protoc 2012;7:872-881.

20 Schechter I, Berger A: On the size of the active site in proteases. I. Papain. 1967. Biochem Biophys Res Commun 2012;425:497-502.

21 Bullard B, Ferguson C, Minajeva A, Leake MC, Gautel M, Labeit D, Ding L, Labeit S, Horwitz J, Leonard KR, Linke WA: Association of the chaperone alphaB-crystallin with titin in heart muscle. J Biol Chem 2004;279:7917-7924

22 Maloyan A, Sanbe A, Osinska H, Westfall M, Robinson D, Imahashi K, Murphy E, Robbins J: Mitochondrial dysfunction and apoptosis underlie the pathogenic process in alpha-B-crystallin desmin-related cardiomyopathy. Circulation 2005;112:3451-3461.

23 Toldo S, Severino A, Abbate A, Baldi A: The role of PDI as a survival factor in cardiomyocyte ischemia. Methods Enzymol 2011;489:47-65.

24 Fricker LD, Gelman JS, Castro LM, Gozzo FC, Ferro ES: Peptidomic analysis of HEK293T cells: effect of the proteasome inhibitor epoxomicin on intracellular peptides. J Proteome Res 2012;11:1981-1990.

25 Kurokawa M, Kornbluth S: Caspases and kinases in a death grip. Cell 2009;138:838-854.

-26 Lopez-Otin C, Hunter T: The regulatory crosstalk between kinases and proteases in cancer. Nat Rev Cancer 2010;10:278-292.

27 Kessenbrock K, Plaks V, Werb Z: Matrix metalloproteinases: regulators of the tumor microenvironment. Cell 2010;141:52-67.

-28 Chalaris A, Adam N, Sina C, Rosenstiel P, Lehmann-Koch J, Schirmacher P, Hartmann D, Cichy J, Gavrilova O, Schreiber S, Jostock T, Matthews V, Hasler R, Becker C, Neurath MF, Reiss K, Saftig P, Scheller J, Rose-John S: Critical role of the disintegrin metalloprotease ADAM17 for intestinal inflammation and regeneration in mice. J Exp Med 2010;207:1617-1624.

29 Morita H, Khanal S, Rastogi S, Suzuki G, Imai M, Todor A, Sharov VG, Goldstein S, O'Neill TP, Sabbah HN: Selective matrix metalloproteinase inhibition attenuates progression of left ventricular dysfunction and remodeling in dogs with chronic heart failure. Am J Physiol Heart Circ Physiol 2006;290:H2522-2527.

30 Jormsjo S, Wuttge DM, Sirsjo A, Whatling C, Hamsten A, Stemme S, Eriksson P: Differential expression of cysteine and aspartic proteases during progression of atherosclerosis in apolipoprotein E-deficient mice. Am J Pathol 2002;161:939-945. 


\section{Cellular Physiology Cell Physiol Biochem 2017;41:358-368 and Biochemistry DOI: 10.1159/000456282 20102017 The Author(s). Published by S. Karger AG, Basel

Wu et al.: Peptidomics Analysis of Cardiomyocytes

- 31 Zieseniss A, Hesse AR, Jatho A, Krull S, Holscher M, Vogel S, Katschinski DM: Cardiomyocyte-Specific Transgenic Expression of Prolyl-4-Hydroxylase Domain 3 Impairs the Myocardial Response to Ischemia. Cell Physiol Biochem 2015;36:843-851.

- 32 van den Berg BH, Tholey A: Mass spectrometry-based proteomics strategies for protease cleavage site identification. Proteomics 2012;12:516-529.

-33 Xia W: Amyloid metabolism and secretases in Alzheimer's disease. Curr Neurol Neurosci Rep 2001;1:422427.

-34 Ashburner M, Ball CA, Blake JA, Botstein D, Butler H, Cherry JM, Davis AP, Dolinski K, Dwight SS, Eppig JT, Harris MA, Hill DP, Issel-Tarver L, Kasarskis A, Lewis S, Matese JC, Richardson JE, Ringwald M, Rubin GM, Sherlock G: Gene ontology: tool for the unification of biology. The Gene Ontology Consortium. Nat Genet 2000;25:25-29.

-35 Cadenas S, Aragones J, Landazuri MO: Mitochondrial reprogramming through cardiac oxygen sensors in ischaemic heart disease. Cardiovasc Res 2010;88:219-228.

-36 Levraut J, Iwase H, Shao ZH, Vanden HT, Schumacker PT: Cell death during ischemia: relationship to mitochondrial depolarization and ROS generation. Am J Physiol Heart Circ Physiol 2003;284:H549-558.

- 37 Chen Q, Moghaddas S, Hoppel CL, Lesnefsky EJ: Reversible blockade of electron transport during ischemia protects mitochondria and decreases myocardial injury following reperfusion. J Pharmacol Exp Ther 2006;319:1405-1412.

-38 Solaini G, Harris DA: Biochemical dysfunction in heart mitochondria exposed to ischaemia and reperfusion. Biochem J 2005;390:377-394.

-39 Liu CL, Li X, Hu GL, Li RJ, He YY, Zhong W, Li S, He KL, Wang LL: Salubrinal protects against tunicamycin and hypoxia induced cardiomyocyte apoptosis via the PERK-eIF2alpha signaling pathway. J Geriatr Cardiol 2012;9:258-268.

40 Wei C, Wang Y, Li M, Li H, Lu X, Shao H, Xu C: Spermine inhibits Endoplasmic Reticulum Stress-induced Apoptosis: a New Strategy to Prevent Cardiomyocyte Apoptosis. Cell Physiol Biochem 2016;38:531-544.

41 Kawaguchi T, Yamagishi SI, Sata M: Structure-function relationships of PEDF. Curr Mol Med 2010;10:302311.

42 Gao X, Zhang H, Zhuang W, Yuan G, Sun T, Jiang X, Zhou Z, Yuan H, Zhang Z, Dong H: PEDF and PEDF-derived peptide 44mer protect cardiomyocytes against hypoxia-induced apoptosis and necroptosis via antioxidative effect. Sci Rep 2014;4:5637.

43 Rahman M, Chan AP, Tang M, Tai IT: A peptide of SPARC interferes with the interaction between caspase 8 and $\mathrm{Bcl} 2$ to resensitize chemoresistant tumors and enhance their regression in vivo. PLoS One 2011;6:e26390.

44 Campbell KB, Chandra M, Kirkpatrick RD, Slinker BK, Hunter WC: Interpreting cardiac muscle force-length dynamics using a novel functional model. Am J Physiol Heart Circ Physiol 2004;286:H1535-1545.

45 Frey N, Luedde M, Katus HA: Mechanisms of disease: hypertrophic cardiomyopathy. Nat Rev Cardiol 2012;9:91-100.

-46 Martin JL, Mestril R, Hilal-Dandan R, Brunton LL, Dillmann WH: Small heat shock proteins and protection against ischemic injury in cardiac myocytes. Circulation 1997;96:4343-4348.

47 Mitra A, Basak T, Datta K, Naskar S, Sengupta S, Sarkar S: Role of alpha-crystallin B as a regulatory switch in modulating cardiomyocyte apoptosis by mitochondria or endoplasmic reticulum during cardiac hypertrophy and myocardial infarction. Cell Death Dis 2013;4:e582.

48 Glembotski CC: Endoplasmic reticulum stress in the heart. Circ Res 2007;101:975-984.

49 Groenendyk J, Sreenivasaiah PK, Kim DH, Agellon LB, Michalak M: Biology of endoplasmic reticulum stress in the heart. Circ Res 2010;107:1185-1197.

50 Taylor M, Burress H, Banerjee T, Ray S, Curtis D, Tatulian SA, Teter K: Substrate-induced unfolding of protein disulfide isomerase displaces the cholera toxin A1 subunit from its holotoxin. PLoS Pathog 2014;10:e1003925.

51 Schroder M, Kaufman RJ: The mammalian unfolded protein response. Annu Rev Biochem 2005;74:739789.

-52 Severino A, Campioni M, Straino S, Salloum FN, Schmidt N, Herbrand U, Frede S, Toietta G, Di Rocco G, Bussani R, Silvestri F, Piro M, Liuzzo G, Biasucci LM, Mellone P, Feroce F, Capogrossi M, Baldi F, Fandrey J, Ehrmann M, Crea F, Abbate A, Baldi A: Identification of protein disulfide isomerase as a cardiomyocyte survival factor in ischemic cardiomyopathy. J Am Coll Cardiol 2007;50:1029-1037. 